\title{
Solid-liquid phase behavior of eutectic solvents containing sugar alcohols
}

\author{
Liliana P. Silva $^{\text {a }}$, Mónia A.R. Martins ${ }^{a}$, Dinis O. Abranches ${ }^{\text {a }}$, Simão P. Pinho ${ }^{\text {b }}$, João A.P. Coutinho ${ }^{\text {a,* }}$ \\ ${ }^{a}$ CICECO - Aveiro Institute of Materials, Department of Chemistry, University of Aveiro, 3810-193 Aveiro, Portugal \\ ${ }^{\mathrm{b}}$ Mountain Research Center - CIMO, Polytechnic Institute of Bragança, 5301-855 Bragança, Portugal
}

\section{A R T I C L E I N F O}

\section{Article history:}

Received 25 January 2021

Revised 27 April 2021

Accepted 1 May 2021

Available online 5 May 2021

\section{Keywords:}

Deep Eutectic Solvents

Sugar alcohols

Cholinium chloride

Solid-liquid equilibrium

Phase diagrams

\begin{abstract}
A B S T R A C T
Mixtures of carbohydrates are often reported in the literature as deep eutectic solvents yet, in most cases, their solid-liquid phase diagrams are poorly characterized and no evidence is available to validate this classification. In this work, the phase diagrams of the binary systems composed of the sugar alcohols mannitol or maltitol and meso-erythritol, xylitol, or sorbitol, were experimentally determined. The results obtained reveal that these systems have a thermodynamic ideal behavior, questioning their classification as deep eutectic solvents and showing that intermolecular hydrogen bonding between the components of a mixture is not a sufficient condition to prepare deep eutectic solvents.

The phase diagrams of the systems composed of mannitol or maltitol and cholinium chloride were also measured in this work. In sharp contrast to the mixtures composed solely by sugar alcohols, and unlike numerous other choline-based eutectic systems reported in the literature, these systems revealed significant deviations to thermodynamic ideality, leading to significant melting temperature depressions. The $\mathrm{Cl}-\mathrm{OH}$ interaction between cholinium chloride and the sugar alcohols is identified as the main reason for these deviations to ideality, paving the way for the rational choice of hydrogen bond acceptors to prepare deep eutectic solvents.
\end{abstract}

(c) 2021 Elsevier B.V. All rights reserved.

\section{Introduction}

Interest in the concepts of sustainability and renewability has been growing over the past two decades in the chemistry and chemical engineering fields [1], particularly in the design of safer and more sustainable solvents [2]. Since most commonly used organic solvents are volatile, toxic, and flammable, efforts have been made to address solvent replacement by more renewable and easily recyclable systems ranging from the use of supercritical $\mathrm{CO}_{2}$ to the application of deep eutectic solvents (DES) [2-5].

Deep eutectic solvents were first reported by Abbott et al. [6], in 2003, as a new class of solvents consisting of binary mixtures of Lewis acids and bases. They are characterized by the low cost of their precursors, preparation simplicity as no synthesis steps are required, low volatility, and environmental friendliness [3-5]. This class of solvents is also generally known to present significantly lower toxicity levels than conventional organic solvents, although the final properties of the solvent depend on the precursors used [7]. These often include cholinium chloride ([Ch]Cl), an essential nutrient and additive in animal feed. Mixtures containing $[\mathrm{Ch}] \mathrm{Cl}$

\footnotetext{
* Corresponding author.

E-mail address: jcoutinho@ua.pt (J.A.P. Coutinho).
}

are, in general, readily biodegradable [8]. Being a good hydrogen bonding acceptor (HBA) and presenting a small melting enthalpy $\left(4.3 \mathrm{~kJ} \mathrm{~mol}^{-1}\right)$ [9], cholinium chloride usually displays a very steep melting curve regardless of the hydrogen bond donning ability of the second component of the mixture [10].

Mixtures of $[\mathrm{Ch}] \mathrm{Cl}$ with naturally occurring compounds such as organic acids, amino acids, sugars, and sugar alcohols[3,4,11-13] are commonly classified and used as DES, as they allow for numerous applications, being safe for human consumption [11]. Despite their high viscosities [14], sugar alcohol-based DES are systems that can be adapted or tuned for a wide range of different applications in food, cosmetic, agrochemical and pharmaceutical industries [15-17]. Despite the increasing interest and the growing number of articles reporting applications using sugar alcohols as DES precursors $[3,4,14,16]$, knowledge about their solid-liquid phase diagrams is scarce $[12,18]$, most likely due to their poor thermal stability. However, the relevance of the information that can be gathered from these phase diagrams on the nature and interactions prevalent on their liquid phase is much valuable [19].

In previous works $[10,20,21]$, we have characterized the solidliquid equilibria (SLE) of several eutectic mixtures composed of sugar alcohols, combined with quaternary ammonium salts. Although commonly reported as DES, the results demonstrated 
that most of these systems do not show significant deviations from the ideal-mixture behavior and, consequently, exhibit low melting temperature depressions. Bearing in mind that the prefix deep should only be used to describe eutectic systems with large deviations from thermodynamic ideality [10], that can also be derived from the measured eutectic temperature [22], these results reinforce the need to further investigate the solid-liquid equilibrium of the numerous deep eutectic solvents reported in the literature based on sugar alcohols.

Aiming at further contributing to the characterization of eutectic systems containing sugar alcohols (mannitol, meso-erythritol, xylitol, sorbitol and maltitol), in this work, the SLE of sugar alcohol + sugar alcohol and cholinium chloride + sugar alcohol mixtures were studied in the full composition range. Results allow to evaluate the nature of these systems and the magnitude of their interactions.

\section{Experimental section}

\subsection{Chemicals}

The source, purity, and melting properties of the compounds studied in this work are detailed in Table 1, while their chemical structures are illustrated in Fig. 1. Cholinium chloride was dried under vacuum at room temperature with constant stirring, for at least $72 \mathrm{~h}$. All the remaining compounds were stored at room temperature and used as received from the supplier as they present very low hygroscopicity. The water content was measured using a Metrohm 831 Karl-Fischer coulometer, with the analyte Hydranal Coulomat AG from Riedel-de Haën and was found to be lower than $600 \mathrm{ppm}$ for cholinium chloride and below $120 \mathrm{ppm}$ for the remaining compounds. The water content of mixtures was also measured and is reported in Table S1.

\section{Solid-Liquid phase diagrams measurements}

Binary mixtures between sugar alcohols, or between $[\mathrm{Ch}] \mathrm{Cl}$ and sugar alcohols, were prepared in different proportions covering the full compositions range (at mole fraction intervals of 0.1 ) by weighting the proper amounts of each pure substance using an analytic balance Mettler Toledo XP205 (repeatability of $0.015 \mathrm{mg}$ ). Due to the hygroscopic character of [Ch]Cl, the eutectic mixtures involving this compound were prepared inside a dryargon glove box at room temperature using an analytical balance from Kern (ALS 220-4 N) with an accuracy of $0.2 \mathrm{mg}$. After the first heating to mix the compounds and immediate crystallization, two experimental methods were applied depending on the physical state of the resulting mixture: $i$ ) for mixtures presenting a pasty consistency, samples were heated in an oil bath under stirring until complete melting. The melting temperatures, measured using a Pt100 probe $( \pm 0.1 \mathrm{~K})$, correspond to the fusion of the last remaining solid. The probe was previously calibrated against a calibrated platinum resistance thermometer, SPRT100 (Fluke-Hart Scientific 1529 Chub-E4), traceable to the National Institute of Standards and Technology (NIST); ii) for mixtures showing complete recrystallization, the samples were grounded in the glovebox, and the powder was filled into a glass capillary. The melting point was then measured in a device model M-565 from Bücchi, with a temperature resolution of $0.1 \mathrm{~K}$. Each procedure was repeated at least three times.

\section{Powder and single crystal $X$-ray diffraction analysis}

Due to the high melting temperatures of almost all systems, making difficult the sampling of the solid phase in equilibrium, only two samples of $[\mathrm{Ch}] \mathrm{Cl}+$ maltitol system $\left(x_{\text {maltitol }}=0.45\right.$ and $\left.x_{\text {maltitol }}=0.70\right)$ were analyzed through X-Ray. Powder X-Ray Diffraction (PXRD) data for all prepared materials were conducted at ambient temperature and at $358 \mathrm{~K}$ for pure choline chloride, on a Empyrean PANalytical diffractometer (Cu Ka1,2 X-radiation, $\lambda 1=1$. $540598 \AA ; \lambda 2=1.544426 \AA$ ), equipped with an PIXcel 1D detector and a flat-plate sample holder in a Bragg-Brentano para-focusing optics configuration ( $45 \mathrm{kV}, 40 \mathrm{~mA})$. Intensity data were collected by the step-counting method (step $0.026^{\circ}$ ), in continuous mode, in the ca. $3.0 \leq 2 \theta \leq 70^{\circ}$ range. The respective diffractograms of the pure compounds, and the solids in equilibrium with the liquid mixtures are depicted in Figure S1 of Supporting Information.

In the case of monocrystal X-Ray analysis, the cell parameters of suitable crystals taken from the selected mixtures were determined on a Bruker SMART Apex II diffractometer equipped with a CCD area detector, with monochromated Mo-Ka radiation $(\lambda=$ $0.71073 \AA$ ) and operating at low temperature $(150 \mathrm{~K})$. The selected crystals were placed at $40 \mathrm{~mm}$ from the CCD and the spots were measured using different counting times (varying from 5 to $30 \mathrm{~s}$ ). After a search in CCDC database for the cell parameters of pure individual compounds and comparison with the parameters obtained during analysis, it was possible to observe that the crystal analyzed by monocrystal X-Ray corresponds to maltitol whose structure is orthorhombic with a space group of $\mathrm{P} 22_{1} 2_{1} 2_{1}$.

\section{Solid-Liquid equilibrium thermodynamics}

The solid-liquid equilibrium curve of a generic component, $i$, in an eutectic-type mixture can be obtained using the following expression:[27]

$\ln \left(x_{i} \cdot \gamma_{i}\right)=\frac{\Delta_{m} h_{i}}{R} \cdot\left(\frac{1}{T_{m, i}}-\frac{1}{T}\right)+\frac{\Delta_{m} C p_{i}}{R} \cdot\left(\frac{T_{m, i}}{T}-\ln \frac{T_{m, i}}{T}-1\right)$

where $x_{i}$ is the mole fraction of component $i, \gamma_{i}$ is its activity coefficient in the liquid phase, $\Delta_{m} h_{i}$ and $T_{m, i}$ are its melting enthalpy and temperature, respectively, $\Delta_{m} C p_{i}$ is its heat capacity change upon melting, $R$ is the ideal gas constant, and $T$ is the absolute temperature of the system. Since the impact of the heat capacity change upon melting on solid-liquid equilibrium is often negligible and considering that this value is not known for many compounds (e.g. [Ch]Cl), the $\Delta_{m} \mathrm{Cp}$ term was neglected [28]. allowing Equation (1) to be simplified to Equation (2)[29]. This assumption has been discussed in detail by us elsewhere [10].

Table 1

Source, purity (according to the supplier), melting temperature $\left(T_{m}\right)$, and melting enthalpy $\left(\Delta_{m} H\right)$ of the substances used in this work.

\begin{tabular}{|c|c|c|c|c|}
\hline Compound & Supplier & Mass Purity \% & $T_{m} / \mathbf{K}$ & $\Delta_{m} H / \mathrm{kJ} \cdot \mathrm{mol}^{-1}$ \\
\hline Cholinium chloride ([Ch]Cl) & Acros Organics & 98 & $597[9]$ & $4.3[9]$ \\
\hline D-Mannitol (Man) & Sigma-aldrich & 98 & $437.3[23]$ & $54.7[23]$ \\
\hline Maltitol (Mal) & Sigma & 98 & $420.0[24]$ & $55.1[24]$ \\
\hline meso-erythritol (ME) & Alfa Aesar & 99 & $391.2[25]$ & $38.9[25]$ \\
\hline Xylitol (Xyl) & Acros Organics & 99 & $365.7[26]$ & $37.4[26]$ \\
\hline Sorbitol (Sor) & Fischer Bioreagents & 98 & $366.5[26]$ & $30.2[26]$ \\
\hline
\end{tabular}


<smiles>C[N+](C)(C)CCO</smiles>

Choline Chloride<smiles>OC[C@@H](O)[C@H](O)[C@H](O)[C@H](O)CO</smiles>

D-Mannitol

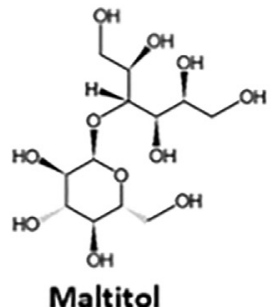

Maltitol<smiles>OC[C@@H](O)[C@H](O)CO</smiles>

meso-erythritol<smiles>OC[C@@H](O)C(O)[C@H](O)CO</smiles>

Xylitol<smiles>OC[C@@H](O)[C@H](O)[C@H](O)[C@H](O)CO</smiles>

Sorbitol

Fig. 1. Chemical structures of the compounds used in this work.

$\ln \left(x_{i} \cdot \gamma_{i}\right)=\frac{\Delta_{m} h_{i}}{R} \cdot\left(\frac{1}{T_{m, i}}-\frac{1}{T}\right)$

Since the melting properties of the compounds studied are known, as reported in Table 1, Equation (2) can be used to assess the activity coefficients from the experimental solid-liquid equilibrium data, allowing for an evaluation of the non-ideality of the liquid phase of the eutectic systems studied. Furthermore, the experimental melting curves can also be compared with those obtained assuming an ideal solution by setting the activity coefficients to unity.

\section{Results}

\subsection{Solid-liquid phase diagrams of sugar alcohol mixtures}

The impact of the differences in size and number of hydroxyl groups on the solid-liquid phase diagrams of binary mixtures composed of mannitol or maltitol and meso-erythritol, xylitol, or sorbitol are investigated in this section. The solid-liquid phase diagrams of the mixtures composed of mannitol and mesoerythritol, xylitol or sorbitol are depicted Fig. 2 (detailed data is listed in Table $\mathbf{S 2}$ in the supporting information) along with the melting curves obtained using Equation (2) assuming an ideal behavior. The experimental activity coefficients were also estimated using Equation (2), which are plotted in Fig. 2 and listed in Table S2 in SI.

The data measured in this work, presented in Fig. 2, were compared against data previously reported by other authors [30-36] and the vast majority is in good agreement. Concerning the pure sugars, the differences between the experimental melting temperatures measured in this work (Table 1) and those from literature are lower than $1.8 \mathrm{~K}$, confirming the consistency of the experimental methodology used. For the system mannitol/erythritol, Shao et al. [31] only reported one melting temperature near the eutectic composition. For the system, mannitol/xylitol, Katona et al. [34] presented data in a limited composition range, in the eutectic region and in the mannitol-rich side. For the system mannitol/sorbitol, there are some discrepancies between the results obtained and those reported by Siniti et al. [35] and by Del Barrio et al. [32], since these authors underestimate the temperatures near the eutectic composition and in the sorbitol rich-side.
Fig. 2 shows that the studied systems involving mannitol are characterized by a single eutectic point close to a mannitol mole fraction of 0.1 and show a nearly ideal behavior on both sides. These systems also have a eutectic temperature and composition similar to that predicted by considering ideal behavior, and close to the melting temperature of the sugar alcohol with the lowest melting point. The activity coefficients estimated from the experimental data, which are very close to 1 (Table S2 and Fig. 2), further support the thermodynamic ideality observer in these systems. This means that the strength of the intermolecular interactions present in these liquid mixtures is similar to those of the liquid phases of the pure components, which is not surprising considering their structural similarity. Even though these systems are simple ideal eutectic mixtures, the results here reported for mixtures containing mannitol still exhibit a considerable temperature depression compared with the melting point of pure mannitol (around $50 \mathrm{~K}$ ).

The results reported in Fig. 2 reveal that these mannitol-based mixtures are not deep eutectic solvents because they lack the appropriate negative deviations to thermodynamic ideality, regardless of the melting temperature depression observed [22]. They are ideal mixtures with SLE phase diagrams with a eutectic point. This significant result, already discussed by us before [9], reaffirms that the existence of intermolecular hydrogen bonding, often used to justify the formation of the liquid phase of DES, is not a sufficient condition to ensure the existence of negative deviations from thermodynamic ideality. Note how both components of these mixtures are excellent hydrogen bond donors and acceptors, but they do not form stronger hydrogen bonding interactions when mixed.

After discussing mannitol-based eutectic systems, the systems composed of the structurally more complex maltitol are now investigated. Replacing mannitol with maltitol allows the probing of the influence of molecular size and number of $-\mathrm{OH}$ groups in the thermodynamic behavior of these systems. The respective SLE phase diagrams of the binary mixtures composed of maltitol and meso-erythritol, xylitol or sorbitol measured in this work are depicted in Fig. 3, along with the ideal liquid phase curves and the experimental activity coefficients. The detailed experimental data and experimental activity coefficients are listed in Table S3 of Supporting Information. The experimental activity coefficients were calculated using Equation (2) and the melting properties of 

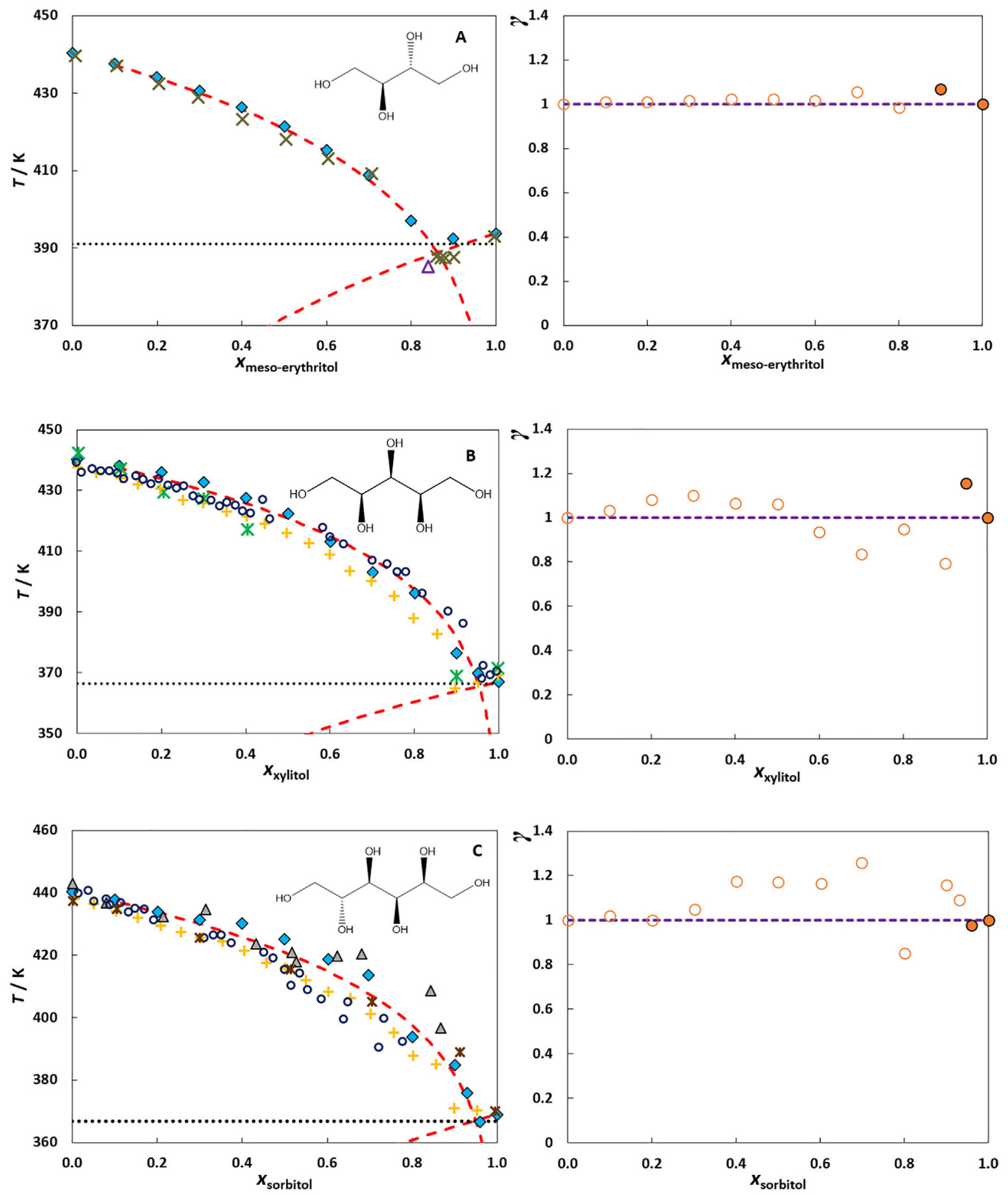

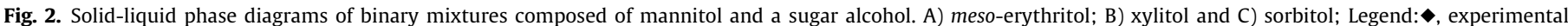

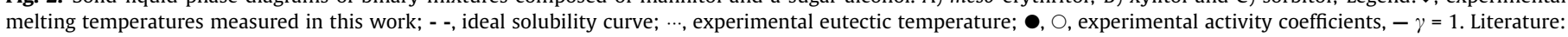

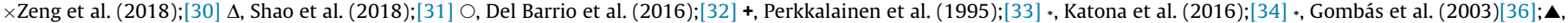
Siniti et al. (1999).[35]

the pure compounds reported in Table 1 . To the best of our knowledge, there are no literature data available for these systems.

Fig. 3 reveals that the SLE phase diagrams of maltitol + mesoerythritol, xylitol, or sorbitol show an ideal behavior in both sides of the phase diagrams. As occurs in mannitol-based systems, the eutectic temperatures of the binary mixtures are significantly above room temperature, and the liquid phase of these mixture behaves almost ideally, with activity coefficients very close to 1 , even if a large asymmetry in terms of size and number of $\mathrm{OH}$ groups is observed when comparing both components of these three binary mixtures. As a consequence of the ideality, the experimental eutectic temperature and composition are very similar to that predicted from Equation $(2)\left(\gamma_{i}^{l}=1\right)$. The studied mannitolbased systems are characterized by a single eutectic point around a mannitol mole fraction of 0.1 , not presenting a significant temperature depression at the eutectic point. The presence of a high number of $-\mathrm{OH}$ groups in the molecules seems to contribute to a similar network of interactions either in a mixed state or as pure 

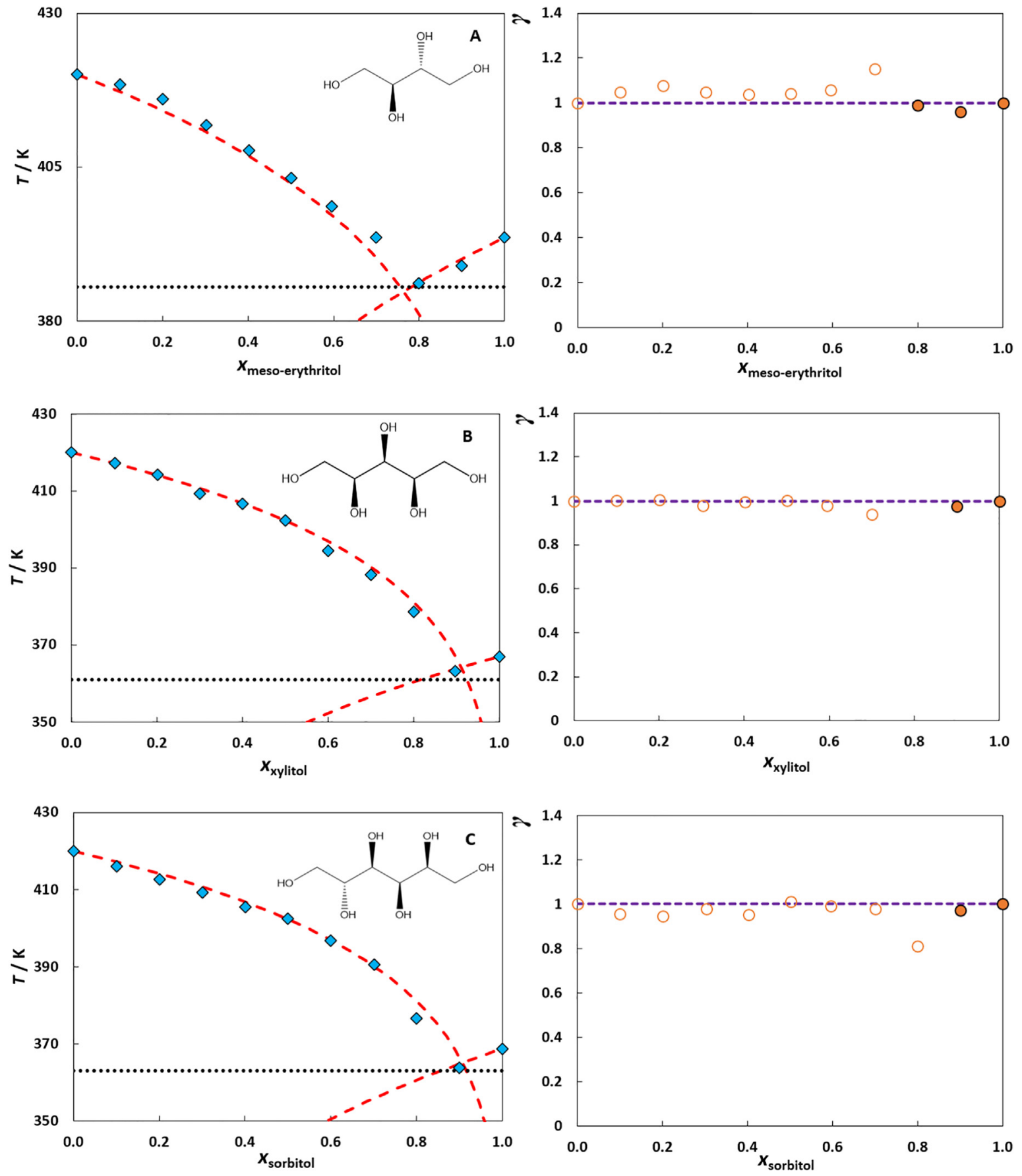

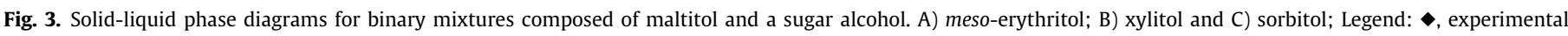
melting temperatures measured in this work; - -, ideal solubility curve; - -, experimental eutectic temperature; $\bullet$, $\bigcirc$, experimental activity coefficients, $-\gamma=1$.

components, while the size and form of the molecules do not contribute much for deviations to ideality.

Closing this set of systems, the SLE phase diagram of mannitol and maltitol was also studied. These results are depicted in Fig. 4 and reported in Table $\mathbf{S} 3$ of the Supporting Information. This system is somewhat different from those reported in Figs. 2 and 3, in the sense that it presents a eutectic point at a different composition. However, this is merely due to their melting properties and not due to intermolecular interactions, as both compounds behave ideally [22]

Analyzing all the binary mixtures containing mannitol and maltitol (Figs. 2, 3 and 4), it is possible to observe that the similar- ities of the chemical structures and the presence of the same functional groups in both compounds of a binary mixture lead to an ideal liquid phase behavior and, consequently, the inability to significantly decrease the eutectic temperature when compared to the melting temperature of the pure compounds, as previously reported for sugars [20]. This reinforces the idea that the existence of intermolecular hydrogen bonding between the components of a mixture does not ensure the formation of deep eutectic solvents. In fact, and as will be discussed in the next section, the cross interactions between the components in a eutectic system need to be stronger than any interaction available to the components in their pure liquid phases to form a deep eutectic solvent. 

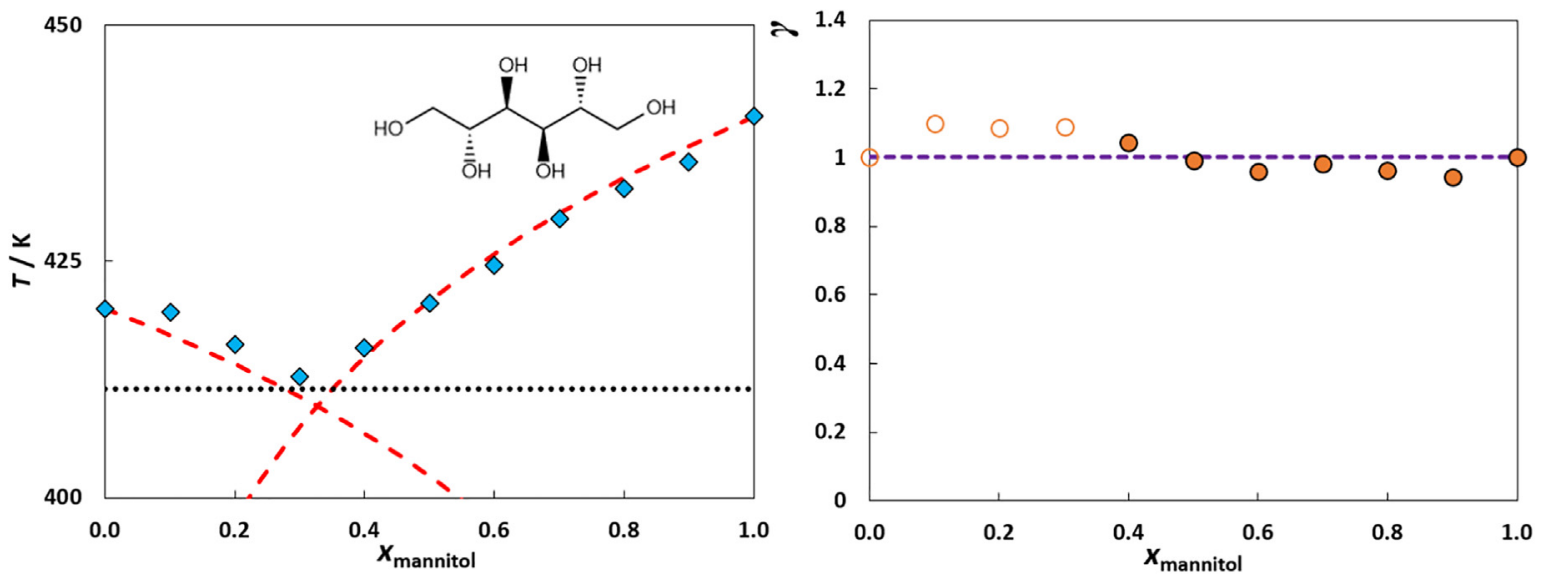

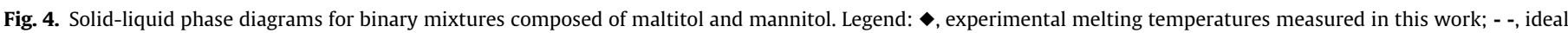
solubility curve; - -, experimental eutectic temperature; $\bullet$, $\bigcirc$, experimental activity coefficients, $-\gamma=1$.

\section{Thermodynamic behavior of $[\mathrm{Ch}] \mathrm{Cl}+$ sugar alcohol systems}

So far, it has been shown that binary mixtures of sugar alcohols behave ideally and therefore are not deep eutectic solvents, despite the ability of these compounds to establish extensive hydrogenbonding networks. Aiming to explore the impact of a well-known HBA in the thermodynamic behavior of sugar alcohol mixtures, the phase diagrams of the systems composed of maltitol or mannitol and $[\mathrm{Ch}] \mathrm{Cl}$ were also investigated. The experimental phase diagrams are depicted in Fig. 5, along with the melting curves calculated by Equation (2) assuming an ideal liquid phase $\left(\gamma_{i}^{l}=1\right)$. Detailed data, including the experimental activity coefficients, are reported in Table S4 of Supporting Information. In order to evaluate the crystal structure of the mixtures, the solid phases were analyzed through X-Ray.

Due to the high melting temperatures of almost all systems, only two samples of the $[\mathrm{Ch}] \mathrm{Cl}+$ maltitol system, one from each side of the phase diagram, were analyzed. The cell parameters obtained were $a=8.16 ; b=12.69 ; c=13.68$; orthorhombic $\mathrm{P}$. According to the CCDC database (version 2020.2.0), we concluded
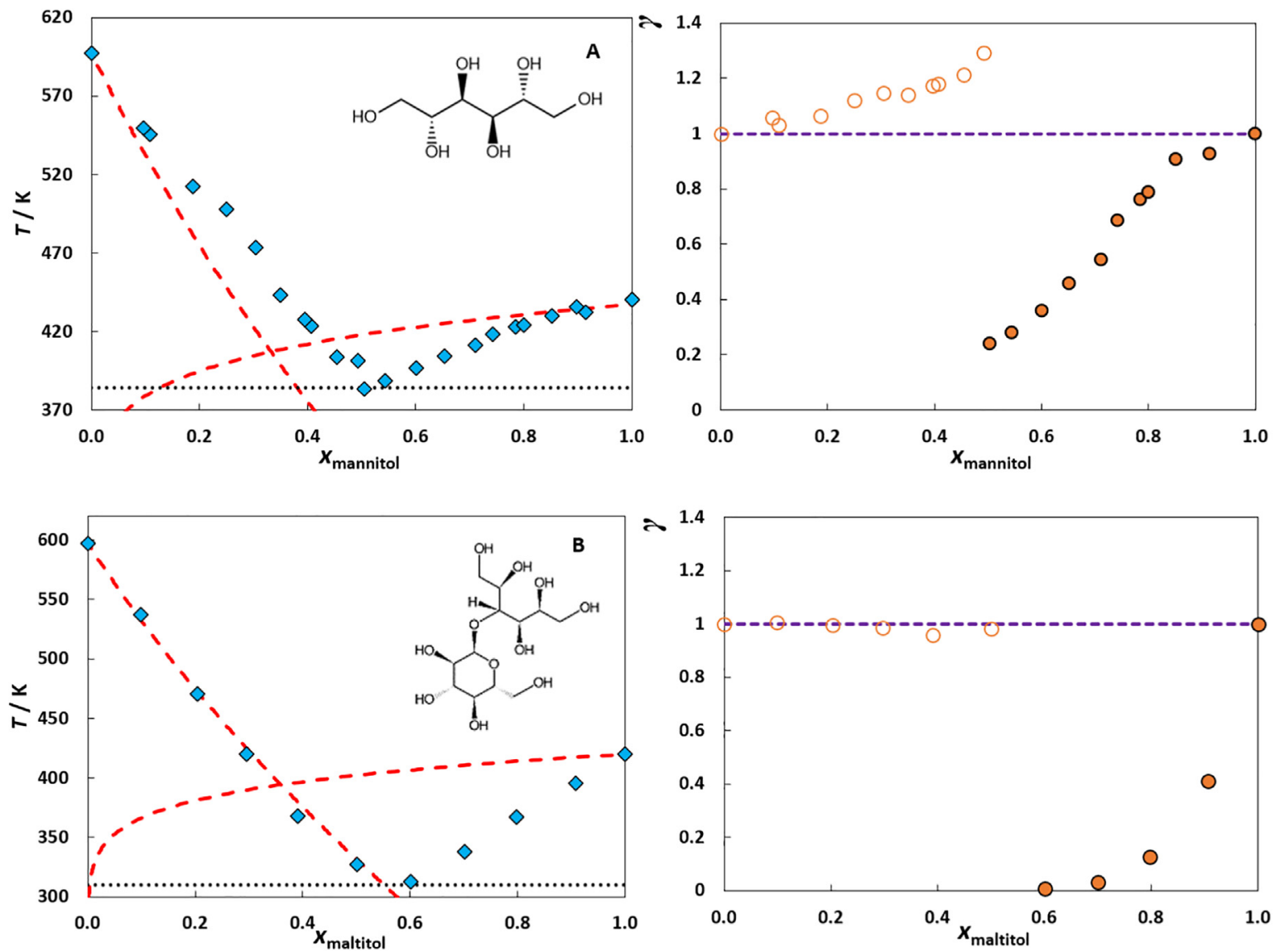

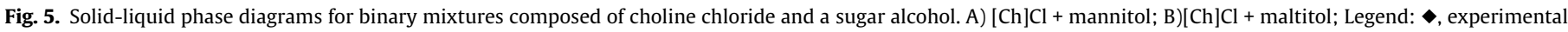
melting temperatures measured in this work; - -, ideal solubility curve; - -, experimental eutectic temperature; $\bullet$, $\bigcirc$, experimental activity coefficients, $-\gamma=1$. 
that it corresponds to maltitol whose space group is $\mathrm{P} 2{ }_{1} 2_{1} 2_{1}$, showing that the addition of the second component does not change the crystal structure and the solubility. Additionally, the diffractograms in Figure S1 show that in the hypertectic region, the solid phase matches the pure maltitol one, confirming the solid phase is not affected by the presence of choline chloride. In the hypotectic region, the solid in equilibrium with a liquid whose maltitol mole fraction is 0.45 presents a diffractogram indicating a combination of the two choline chloride polymorphs, which is quite probable attending to the equilibrium temperature level at that composition.

There is a sharp contrast between the results reported in Fig. 5 and those reported in Figs. 2, 3 and 4. Contrary to the systems composed only of sugar alcohols, which displayed an ideal thermodynamic behavior, cholinium chloride can induce negative deviations to ideality on mannitol and maltitol. This leads to significant melting temperature depressions not obtainable using the other compounds previously studied, with depressions of $54 \mathrm{~K}$ and $107 \mathrm{~K}$ for the systems $[\mathrm{Ch}] \mathrm{Cl}+$ mannitol and $[\mathrm{Ch}] \mathrm{Cl}+$ maltitol, respectively, when compared to the melting temperature of the pure sugars. Note, however, that the $[\mathrm{Ch}] \mathrm{Cl}$ activity coefficients show positive deviations from ideality when mixed with mannitol and a quasi-ideal behavior when mixed with maltitol. More specifically, the experimental activity coefficients for the system $\mathrm{ChCl}+$ mannitol are uncommon; in the large series of binary systems containing $\mathrm{ChCl}$ already studied only a few present positive deviations from ideality in the $\mathrm{ChCl}$ side, which might be related to the to changes in the crystalline form of $\mathrm{ChCl}$ or the formation of some intermediate compound. However, the results are comparable with those for mixtures of [Ch]Cl with meso-erythritol, xylitol, sorbitol previously studied by us [21], where the polyalcohol exhibited negative deviations from ideality.

The sugar alcohol negative deviations to ideality discussed in the previous paragraph hint at the formation of hydrogen bonds between their hydroxyl groups and the chloride anion of [Ch]Cl. This specific interaction is stronger than the typical $\mathrm{OH}-\mathrm{OH}$ hydrogen bonding found in the pure liquid phases of the sugar alcohols and explains the negative deviations to ideality these compounds display when mixed with $[\mathrm{Ch}] \mathrm{Cl}$. On the other hand, the hydrogen bond between the chloride anion of $[\mathrm{Ch}] \mathrm{Cl}$ and the hydroxyl groups of the sugar alcohols is still weaker than the interaction between the chloride and the hydroxide group of the choline cation. Thus, $[\mathrm{Ch}] \mathrm{Cl}$ presents either an ideal behavior or positive deviations from ideality, since the formation of new $\mathrm{Cl}-\mathrm{OH}$ contacts with the sugar alcohols decreases the number of $\mathrm{Cl}-\mathrm{OH}$ contacts between both ions of $[\mathrm{Ch}] \mathrm{Cl}$.

The difference in the magnitude of the negative deviations to ideality displayed by maltitol and by mannitol, when mixed with $[\mathrm{Ch}] \mathrm{Cl}$, can be explained by the number of hydroxyl groups of these compounds. Maltitol has a much larger number of hydroxyl groups than mannitol, which means that the former is able to establish more $\mathrm{Cl}-\mathrm{OH}$ hydrogen bonds than the latter. This also explains why $[\mathrm{Ch}] \mathrm{Cl}$ behaves ideally when mixed with maltitol (as opposed to showing positive deviations to ideality), as its greater number of $-\mathrm{OH}$ groups makes the number and magnitude of interactions in the mixture more significant, and similar to the magnitude observed in pure $[\mathrm{Ch}] \mathrm{Cl}$.

The results here discussed reveal that the prototypical hydrogen bond acceptor $[\mathrm{Ch}] \mathrm{Cl}$ is unable to show negative deviations to ideality, as observed in many other works [37-40], reiterating its inability to establish stronger interactions with other compounds than with itself in the liquid phase. The addition of [Ch]Cl to the sugar-alcohol gives rise to strong interactions between the components inducing strong negative deviations from ideality in the sugar alcohol rich side, which is a behavior observed in many other systems $[41,42]$, showing that a small addition of [Ch]Cl allows for a significant decrease of the melting temperature of the pure sugar alcohol. Although the eutectic temperature is significantly below from those predicted by the ideal mixture, obeying the condition needed to be a DES, the melting temperatures of these mixtures are still above room temperature, in stark contradiction to what is often reported in the literature [4,43-46] where these mixtures are reported to be liquid at room temperature.

\section{Conclusions}

In this work, mixtures composed of sugar alcohols, and mixtures of $[\mathrm{Ch}] \mathrm{Cl}$ with sugar alcohols were investigated by measuring the solid-liquid equilibrium phase diagrams of their binary mixtures in the entire composition range. From these experimental data the activity coefficients of the components in the liquid phase were calculated, allowing the data to be interpreted in terms of intermolecular interactions.

The studied systems involving the combination of two sugar alcohols were all found to be thermodynamically ideal. These results reveal that, although sugar alcohol systems have been reported as DES in the literature, they do not establish new interactions not found in the pure components and should not be classified as deep. This reinforces the idea that the presence of intermolecular hydrogen bonding in a mixture does not necessarily lead to negative deviations to thermodynamic ideality, and is thus not a sufficient condition for the formation of DES.

Regarding the systems composed of $[\mathrm{Ch}] \mathrm{Cl}$ and sugar alcohols, the activity coefficient data revealed that while the sugar alcohols exhibit significant negative deviations from ideality, $[\mathrm{Ch}] \mathrm{Cl}$ behaves ideally or displays positive deviations to ideality. In fact, the presence of $[\mathrm{Ch}] \mathrm{Cl}$ induces a significant temperature depression, with depressions of $54 \mathrm{~K}$ and $107 \mathrm{~K}$ for the systems [Ch] $\mathrm{Cl}+$ mannitol and $[\mathrm{Ch}] \mathrm{Cl}+$ maltitol, respectively, when compared to the melting temperature of the pure sugars. The asymmetric thermodynamic behavior of these systems was interpreted in terms of intermolecular interactions. It was shown that the interaction $\mathrm{Cl}-\mathrm{OH}$, being stronger than the typical $\mathrm{OH}-\mathrm{OH}$ hydrogen bonding found in the pure liquid phases of the sugar alcohols, was responsible for the negative deviations of the sugar alcohols and, being weaker than the interaction between the chloride anion and the cholinium cation in cholinium chloride, was also responsible for the positive deviations of [Ch]Cl.

\section{CRediT authorship contribution statement}

Liliana P. Silva: Conceptualization, Data curation, Formal analysis, Methodology, Writing - original draft, Writing - review \& editing. Mónia A.R. Martins: Conceptualization, Formal analysis, Supervision, Writing - review \& editing. Dinis O. Abranches: Conceptualization, Formal analysis, Writing - review \& editing. Simão P. Pinho: Conceptualization, Formal analysis, Supervision, Funding acquisition, Writing - review \& editing. João A.P. Coutinho: Conceptualization, Formal analysis, Funding acquisition, Supervision, Writing - review \& editing.

\section{Declaration of Competing Interest}

The authors declare that they have no known competing financial interests or personal relationships that could have appeared to influence the work reported in this paper.

\section{Acknowledgments}

This work was developed within the scope of the project CICECO-Aveiro Institute of Materials, UIDB/50011/2020 \& 
UIDP/50011/2020, and CIMO-Mountain Research Center, UIDB/00690/2020, both financed by national funds through the Portuguese Foundation for Science and Technology(FCT)/MCTES. L.P.S. acknowledges FCT for her PhD grant (SFRH/ $\mathrm{BD} / 135976 / 2018$ ).

\section{References}

[1] T.P. Anastas, M. Kirchhoff, M. Origins, Current Status, and Future Challenges of Green Chemistry, Acc. Chem. Res. 35 (2002) 686-694, https://doi.org/10.1021/ ar010065m.

[2] W. Leitner, Supercritical Carbon Dioxide as a Green Reaction Medium for Catalysis, Acc. Chem. Res. 35 (2002) 746-756, https://doi.org/10.1021/ ar010070q.

[3] Y. Dai, J. van Spronsen, G.J. Witkamp, R. Verpoorte, Y.H. Choi, Natural Deep Eutectic Solvents as New Potential Media for Green Technology, Anal. Chim. Acta 766 (2013) 61-68, https://doi.org/10.1016/j.aca.2012.12.019.

[4] A. Paiva, R. Craveiro, I. Aroso, M. Martins, R.L. Reis, A.R.C. Duarte, Natural Deep Eutectic Solvents - Solvents for the 21st Century, ACS Sustain. Chem. Eng. 2 (2014) 1063-1071, https://doi.org/10.1021/sc500096j.

[5] E.L. Smith, A.P. Abbott, K.S. Ryder, Deep Eutectic Solvents (DESs) and Their Applications, Chem. Rev. 114 (2014) 11060-11082, https://doi.org/10.1021/ cr300162p.

[6] A.P. Abbott, G. Capper, D.L. Davies, R.K. Rasheed, V. Tambyrajah, Novel Solvent Properties of Choline Cholride Urea Mixtures, Chem. Commun. 70-71 (2003), https://doi.org/10.1039/B210714G.

[7] A.P. Abbott, D. Boothby, G. Capper, D.L. Davies, R.K. Rasheed, Deep Eutectic Solvents Formed between Choline Chloride and Carboxylic Acids: Versatile Alternatives to Ionic Liquids, J. Am. Chem. Soc. 126 (2004) 9142-9147, https:// doi.org/10.1021/ja048266j.

[8] K. Radošević, M. Cvjetko Bubalo, V. Gaurina Srček, D. Grgas, T. Landeka Dragičević, R.I. Redovniković, Evaluation of Toxicity and Biodegradability of Choline Chloride Based Deep Eutectic Solvents, Ecotoxicol. Environ. Saf. 112 (2015) 46-53, https://doi.org/10.1016/j.ecoenv.2014.09.034.

[9] L. Fernandez, L.P. Silva, M.A.R. Martins, O. Ferreira, J. Ortega, S.P. Pinho, J.A.P. Coutinho, Indirect Assessment of the Fusion Properties of Choline Chloride from Solid-Liquid Equilibria Data, Fluid Phase Equilib. 448 (2017) 9-14, https://doi.org/10.1016/j.fluid.2017.03.015.

[10] M.A.R. Martins, S.P. Pinho, J.A.P. Coutinho, Insights into the Nature of Eutectic and Deep Eutectic Mixtures, J. Solution Chem. 48 (2018) 962-968, https://doi. org/10.1007/s10953-018-0793-1.

[11] M. Faggian, S. Sut, B. Perissutti, V. Baldan, I. Grabnar, S.D. Acqua, Natural Deep Eutectic Solvents (NADES) as a Tool for Bioavailability Improvement : Pharmacokinetics of Rutin Dissolved in Proline / Glycine after Oral Administration in Rats : Possible Application in Nutraceuticals, Molecules 21 (2016) 1-11, https://doi.org/10.3390/molecules21111531.

[12] Z. Maugeri, P. Domínguez De María, Novel Choline-Chloride-Based DeepEutectic-Solvents with Renewable Hydrogen Bond Donors: Levulinic Acid and Sugar-Based Polyols, RSC Adv. 2 (2012) 421-425, https://doi.org/10.1039/ c1ra00630d.

[13] L.J.B.M. Kollau, M. Vis, A. Van Den Bruinhorst, G. De With, R. Tuinier, Activity Modelling of the Solid-Liquid Equilibrium of Deep Eutectic Solvents, Pure and Applied Chemistry; De Gruyter 91 (2019) 1341-1349, https://doi.org/ 10.1515/pac-2018-1014.

[14] A.P. Abbott, R.C. Harris, K.S. Ryder, C. D’Agostino, L.F. Gladden, M.D. Mantle, Glycerol Eutectics as Sustainable Solvent Systems, Green Chem. 13 (2011) 8290, https://doi.org/10.1039/c0gc00395f.

[15] M. Espino, M. de los Ángeles Fernández, F.J.V. Gomez, M.F. Silva, Natural Designer Solvents for Greening Analytical Chemistry. TrAC - Trends Anal. Chem. 76 (2003) 126-136, https://doi.org/10.1016/j.trac.2015.11.006.

[16] M. Francisco, A. Van Den Bruinhorst, M.C. Kroon, Low-Transition-Temperature Mixtures (LTTMs): A New Generation of Designer Solvents, Angew. Chemie Int. Ed. 52 (2013) 3074-3085, https://doi.org/10.1002/anie.201207548.

[17] C.F. Araujo, J.A.P. Coutinho, M.M. Nolasco, S.F. Parker, P.J.A. Ribeiro-Claro, S. Rudić, B.I.G. Soares, P.D. Vaz, Inelastic Neutron Scattering Study of Reline: Shedding Light on the Hydrogen Bonding Network of Deep Eutectic Solvents, Phys. Chem. Chem. Phys. 19 (2017) 17998-18009, https://doi.org/10.1039/ c7cp01286a.

[18] H. Wang, S. Liu, Y. Zhao, J. Wang, Z. Yu, Insights into the Hydrogen Bond Interactions in Deep Eutectic Solvents Composed of Choline Chloride and Polyols, ACS Sustain. Chem. Eng. 7 (2019) 7760-7767, https://doi.org/10.1021/ acssuschemeng.8b06676.

[19] Miller E, H. R. Sucrose Crystallization in Caramel. J Food Eng. 153 (2015) 28-38, doi.org/10.1016/j.jfoodeng.2014.11.028

[20] L.P. Silva, L. Fernandez, J.H.F. Conceiçao, M.A.R. Martins, A. Sosa, J. Ortega, S.P. Pinho, J.A.P. Coutinho, Design and Characterization of Sugar-Based Deep Eutectic Solvents Using Conductor-like Screening Model for Real Solvents, ACS Sustain. Chem. Eng. 6 (2018) 10724-10734, https://doi.org/10.1021/ acssuschemeng.8b02042.

[21] P.L. Silva, A. R.M. Martins, H. F.J. Conceição, P.S. Pinho, A. P.J. Coutinho, Eutectic Mixtures Based on Polyalcohols as Sustainable Solvents: Screening and Characterization, ACS Sustain. Chem. \& Eng. 8 (2020) 15317-15326, https:// doi.org/10.1021/acssuschemeng.0c05518.
[22] L.J.B.M. Kollau, M. Vis, A. Van Den Bruinhorst, A.C.C. Esteves, R. Tuinier, Quantification of the Liquid Window of Deep Eutectic Solvents, Chem Commun. 54 (2018) 13351-13354, https://doi.org/10.1039/c8cc05815f.

[23] B. Tong, R.-B. Liu, C.-G. Meng, F.-Y. Yu, S.-H. Ji, Z.-C. Tan, Heat Capacities and Nonisothermal Thermal Decomposition Reaction Kinetics of D-Mannitol, J. Chem. \& Eng. Data 55 (2009) 119-124, https://doi.org/ 10.1021/je900285w.

[24] N. Lebrun, J.C. Van Miltenburg, O. Bustin, M. Descamps, Calorimetric Fragility of Maltitol, Phase Transitions 76 (2003) 841-846, https://doi.org/10.1080/ 0141159031000085723.

[25] A.J.L. Jesus, L.I.N. Tomé, M.E. Eusébio, J.S. Redinha, Enthalpy of Sublimation in the Study of the Solid State of Organic Compounds. Application to Erythritol and Threitol, J. Phys. Chem. B 109 (2005) 18055-18060, https://doi.org/ $10.1021 / \mathrm{jp} 051621 \mathrm{n}$.

[26] G. Barone, G. Della Gatta, D. Ferro, V. Piacente, Enthalpies and Entropies of Sublimation, Vaporization and Fusion of Nine Polyhydric Alcohols, J. Chem. Soc. Faraday Trans. 86 (1990) 75-79, https://doi.org/10.1039/FT9908600075.

[27] J.M. Prausnitz, R.N. Lichtenthaler, E.G. Azevedo, Molecular Thermodynamics of Fluid-Phase, Equilibria 2 (1970), https://doi.org/10.1016/0021-9614(70) 90078-9.

[28] Elliott J.R., Lira C.T., Introductory Chemical Engineering Thermodynamics, 2nd edition, Prentiche Hall. (2012).

[29] J.A.P. Coutinho, S.I. Andersen, E.H. Stenby, Evaluation of Activity Coefficient Models in Prediction of Alkane Solid-Liquid Equilibria, Fluid Phase Equilib. 103 (1995) 23-39, https://doi.org/10.1016/0378-3812(94)02600-6.

[30] J.L. Zeng, Y.H. Chen, L. Shu, L.P. Yu, L. Zhu, L. SongBin, Z. Cao, L.X. Sun, Preparation and Thermal Properties of Exfoliated Graphite/Erythritol/Mannitol Eutectic Composite as Form-Stable Phase Change Material for Thermal Energy Storage, Sol. Energy Mater. Sol. Cells. 178 (2018) 84-90, https://doi.org/ 10.1016/j.solmat.2018.01.012.

[31] X.F. Shao, C. Wang, Y.J. Yang, B. Feng, Z.Q. Zhu, W.J. Wang, Y. Zeng, L.W. Fan, Screening of Sugar Alcohols and Their Binary Eutectic Mixtures as Phase Change Materials for Low-to-Medium Temperature Latent Heat Storage. (I): Non-Isothermal Melting and Crystallization Behaviors, Energy 160 (2018) 1078-1090, https://doi.org/10.1016/j.energy.2018.07.081.

[32] E. Palomo Del Barrio, R. Cadoret, J. Daranlot, F. Achchaq, New Sugar Alcohols Mixtures for Long-Term Thermal Energy Storage Applications at Temperatures between $70{ }^{\circ} \mathrm{C}$ and $100{ }^{\circ} \mathrm{C}$, Sol. Energy Mater. Sol. Cells 155 (2016) 454-468, https://doi.org/10.1016/j.solmat.2016.06.048.

[33] P. Perkkalainen, H. Halttunen, I. Pitkänen, Solid State Co-Crystallization of Sugar Alcohols Measured with Differential Scanning Calorimetry, Thermochim. Acta 269-270 (1995) 351-359, https://doi.org/10.1016/00406031(95)02539-1.

[34] G. Katona, P. Sipos, P. Frohberg, J. Ulrich, P. Szabó-Révész, O. Jójárt-Laczkovich, Study of Paracetamol-Containing Pastilles Produced by Melt Technology, J. Therm. Anal. Calorim. 123 (2016) 2549-2559, https://doi.org/10.1007/s10973015-5223-7.

[35] M. Siniti, S. Jabrane, J.M. Létoffé, Study of the Respective Binary Phase Diagrams of Sorbitol with Mannitol, Maltitol and Water. Thermochim. Acta 325 (1999) 171-180, https://doi.org/10.1016/S0040-6031(98)00576-0.

[36] Á. Gombás, P. Szabó-Révész, G. Regdon, I. Erös, Study of Thermal Behaviour of Sugar Alcohols, J. Therm. Anal. Calorim. 73 (2003) 615-621, https://doi.org/ 10.1023/A:1025490432142.

[37] O.D. Abranches, O.R. Martins, P.L. Silva, A. R.M. Martins, P.S. Pinho, A. P.J. Coutinho, Liquefying Compounds by Forming Deep Eutectic Solvents: A Case Study for Organic Acids and Alcohols, J. Phys. Chem. B. 124 (2020) 4174-4184, https://doi.org/10.1021/acs.jpcb.0c02386.

[38] E.A. Crespo, L.P. Silva, M.A.R. Martins, L. Fernandez, J. Ortega, O. Ferreira, G. Sadowski, C. Held, P. Pinho, A.P. Coutinho, Characterization and Modeling of the Liquid Phase of Deep Eutectic Solvents Based on Fatty Acids / Alcohols and Choline Chloride, Ind. Eng. Chem. Res. 56 (2017) 12192-12202, https://doi.org/ 10.1021/acs.iecr.7b02382.

[39] D.O. Abranches, M. Larriba, L.P. Silva, M. Melle-Franco, J.F. Palomar, S.P. Pinho, J.A.P. Coutinho, Using COSMO-RS to Design Choline Chloride Pharmaceutical Eutectic Solvents, Fluid Phase Equilib. 497 (2019) 71-78, https://doi.org/ 10.1016/j.fluid.2019.06.005.

[40] D.O. Abranches, L.P. Silva, M.A.R. Martins, L. Fernandez, S.P. Pinho, J.A.P. Coutinho, Can Cholinium Chloride Form Eutectic Solvents with Organic Chloride-Based Salts?, Fluid Phase Equilib. 493 (2019) 120-126, https://doi. org/10.1016/j.fluid.2019.04.019.

[41] E.A. Crespo, L.P. Silva, M.A.R. Martins, M. Bülow, O. Ferreira, G. Sadowski, C. Held, S.P. Pinho, J.A.P. Coutinho, The Role of Polyfunctionality in the Formation of [Ch]Cl-Carboxylic Acid-Based Deep Eutectic Solvents, Ind. Eng. Chem. Res. 57 (2018) 11195-11209, https://doi.org/10.1021/acs.iecr.8b01249.

[42] L.P. Silva, C.F. Araújo, D.O. Abranches, M. Melle-Franco, M.A.R. Martins, M.M. Nolasco, P.J.A. Ribeiro-Claro, S.P. Pinho, J.A.P. Coutinho, What a Difference a Methyl Group Makes-Probing Choline-Urea Molecular Interactions through Urea Structure Modification, Phys. Chem. Chem. Phys. 21 (2019) 1827818289, https://doi.org/10.1039/c9cp03552d.

[43] Y. Dai, G.J. Witkamp, R. Verpoorte, Y.H. Choi, Tailoring Properties of Natural Deep Eutectic Solvents with Water to Facilitate Their Applications, Food Chem. 187 (2015) 14-19, https://doi.org/10.1016/j.foodchem.2015.03.123.

[44] YH Choi, J van Spronsen, Y Dai, M Verberne, F Hollmann, IW Arends, G Witkamp, Are Natural Deep Eutectic Solvents the Missing Link in Understanding Cellular Metabolism and Physiology?, Plant Physiol 156 (2011) 1701-1705, https://doi.org/10.1104/pp.111.178426. 
[45] Y. Dai, K. Ho Row, Application of Natural Deep Eutectic Solvents in the Extraction of Quercetin from Vegetables, Molecules 24 (2019) 2300, https:// doi.org/10.3390/molecules24122300.

[46] D.Z. Troter, Z.B. Todorović, D.R. Đokić-Stojanović, B.S. Đordević, V.M. Todorović, S.S. Konstantinović, V.B. Veljković, The Physicochemical and
Thermodynamic Properties of the Choline Chloride-Based Deep Eutectic Solvents, J. Serbian Chem. Soc. 82 (2017) 1039-1052, https://doi.org/ 10.2298/JSC170225065T. 